\title{
Etnografia como abordagem teórico-metodológica em estudos de crítica de mídia ${ }^{1}$
}

\section{Ethnography as a theoretical-methodological approach to newsmaking studies}

Lívia de Souza Vieira²

1 Uma primeira versão deste trabalho foi apresentada no I Simpósio de crítica de mídia: Como criticam os que criticam, realizado em 21 e 22 de setembro de 2017 na Universidade Federal de Santa Catarina (UFSC).

Considero importante mencionar que as reflexões deste artigo integram a tese da autora "Métricas editoriais no jornalismo online: ética e cultura profissional na relação com audiências ativas", apresentada em fevereiro de 2018 no Programa de Pós-Graduação em Jornalismo da UFSC. 


\section{Resumo}

A abordagem teórica do newsmaking, focada na produção jornalística, apresenta desafios que impactam diretamente as pesquisas em jornalismo: dificuldade de entrar nas redações, tensão nas entrevistas com jornalistas, efetividade no relato do trabalho de campo. Talvez por isso grande parte dos estudos se detenham na análise do produto, em especial quando se direcionam à crítica de mídia. Por outro lado, conhecer as etapas que antecedem o produto final, procurando mapear as controvérsias, pode ser bastante oportuno para as teorias desse campo. Assim, defendemos e propomos a utilização da etnografia, segundo as bases da teoria ator-rede de Latour, como abordagem teórico-metodológica possível para os estudos de crítica de mídia.

\section{Palavras-chave}

Etnografia, newsmaking, jornalismo, crítica de mídia, teoria ator-rede.

\section{Abstract}

The theoretical approach of newsmaking focused on journalistic production presents challenges that directly impact research in journalism: the difficulty to enter newsrooms, the tension in interviews with journalists, the effectiveness in reporting field work. Perhaps, for this reason, most studies focus on analyzing the product, especially considering media criticism. On the other hand, knowing the steps that precede the final product, and mapping the controversies may be quite useful for theories in this field. Thus, we defend and propose the use of ethnography, according to the actor-network theory of Latour, as a possible theoretical-methodological approach for media criticism studies.

\section{Keywords}

Ethnography, newsmaking, journalism, media criticism, actor-network theory. 
A notícia é uma forma de conhecer aspectos do presente. Por isso, a análise de sua produção lança pistas sobre o mundo que nos cerca (FONTCUBERTA, 1993) e é essencial para a própria compreensão de seu significado (PEREIRA JUNIOR, 2005; TRAQUINA, 1988). Trata-se de uma das fases do processo comunicativo, assim como a circulação e o consumo, numa relação não linear, mas de circuito e interrelação constantes (HALL, 2009).

Sob o ponto de vista da pesquisa, o processo de produção jornalística tem sido objeto de crescente interesse, mas nem sempre foi assim. Alsina (2009, p. 59) afirma que a produção é o "lado escuro da Lua" e, através de um efeito de ocultação, a mídia muitas vezes se apresenta como simples transmissor de informação. Há uma razão política para isso: Wolf (2012) destaca a histórica contraposição entre a pesquisa "administrativa" e a "crítica" - "isto é, a pesquisa americana, de um lado, marcadamente empírica e caracterizada por finalidades cognitivas internas ao sistema da mídia; e a pesquisa europeia, de outro, teoricamente orientada e atenta às relações gerais entre sistema social e meios de comunicação de massa" (p. 12).

Entre os anos 1920 e 1970, houve o desenvolvimento de diversas teorias do processo comunicativo. Hohlfeldt (2014, p. 187) as agrupa em alguns blocos, inspirado por Wolf: teoria hipodérmica ou de manipulação; teorias empíricas de campo e experimentais; teoria funcionalista; teoria estruturalista; teoria crítica - mais conhecida como Escola de Frankfurt; estudos culturais; e teorias comunicativas (matemática, semiótica e linguística).

Diante dessa diversidade de correntes teóricas, muito da evolução da pesquisa sobre mídia foi possível graças à confluência entre a sociologia do conhecimento e o estudo das comunicações de massa (mass communication studies). "A crise pareceu ser resolvida e, desde o final dos anos 70/início dos anos 80, algumas temáticas gerais e alguns setores específicos de pesquisa coagulam em torno de si interesses, esforços de análise e reflexão teórica" (WOLF, 2012, p. 14). E é nessa época que ganham força os estudos sobre o processo de produção da notícia - o newsmaking -, que Wolf classifica como uma nova tendência de pesquisa. 
De forma mais ampla, o newsmaking "procura descrever como as exigências organizativas e a organização do trabalho e dos processos produtivos influenciam na construção da notícia" (PEREIRA JÚNIOR, 2005, p. 8). Alsina (2009) afirma que não se pode cair na falácia de considerar a mídia como construtora da realidade sem levar em conta a interação da audiência. "Por isso, precisamos deixar bem claro que a construção social da realidade por parte da mídia é um processo de produção, circulação e reconhecimento" (p. 47). Critérios de noticiabilidade e valores-notícia, seleção de notícias (gatekeeping), rotinas de produção, cultura profissional, constrangimentos organizacionais, ideologias e relação com as fontes de informação constituem interesses desse tipo de investigação.

\section{A influência da sociologia nos estudos de newsmaking}

Nesse sentido, é inegável o predomínio da abordagem sociológica nos estudos de newsmaking, que investigam o impacto da mídia na sociedade. Para tal, dedicam-se à estruturação de sistemas, modelos ou grandes categorias de análise, a depender da nomenclatura utilizada por cada autor ou autora. A formulação da teoria se dá, portanto, pela generalização que busca explicar fenômenos sociais. Tem força a metodologia interpretativa, que procura descobrir os significados das ações sociais. "Um acontecimento em si mesmo não é tão importante, o mais importante é o que os agentes sociais interpretam que ele é. [...] Com a metodologia interpretativa, nos deparamos com um processo que busca uma compreensão global dos fenômenos e das situações que estuda" (ALSINA, 2009, p. 27).

Tuchman (1978), em sua "rotinização do inesperado", investigou como os media contribuem para a construção social da realidade e como as rotinas de trabalho determinam a produção da notícia. A autora organiza diversas categorizações, como tipos de notícias (duras, leves, súbitas, em desenvolvimento e em sequência); critérios para avaliação de fontes de informação (autoridade, produtividade e credibilidade); distribuição da rede noticiosa (por área geográfica, especialização organizacional e temática); ordenação do tempo (expectativa de acontecimentos, 
agenda, ritmo de trabalho e critérios de noticiabilidade); entre outras (PIMENTEL; TEMER, 2012). Para tal, Tuchman fez uma pesquisa etnográfica por 10 anos (1966 a 1976) em um canal de TV, três jornais impressos dos EUA e na redação da prefeitura de Nova York. Seu trabalho foi essencial para o entendimento (pelo menos parcial) dos agentes que constroem a notícia e a fazem ser o que são.

Schudson igualmente desenvolveu, desde o final da década de 1970, importante investigação sobre a notícia como forma cultural e a mídia como uma instituição social. Segundo ele, a ação pessoal, a ação social e a ação cultural, em interrelação, são as três principais explicações para que as notícias sejam como são.

A análise sociológica de Gans também foi realizada na década de 1970, a chamada era de ouro do jornalismo americano. Segundo ele, os sociólogos estão mais preocupados com os papeis que as pessoas desempenham e com as posições que elas ocupam na organização do que com personalidades individuais. O autor investigou durante 10 anos quatro grandes redações de TV e revistas dos EUA, estudando valores, padrões profissionais e pressões que moldam o julgamento dos jornalistas (GANS, 2004). Sua ênfase se deu na seleção de notícias, mais do que na produção, e seu foco estava nas regras não escritas.

Shoemaker e Reese, sob a perspectiva da sociologia da mídia, atualizaram, em 2014, o livro Mediando a mensagem, cuja primeira edição é de 1991 e a segunda, de 1996. Em 1999, foi eleito pela revista Journalism \& Mass Communication Quarterly um dos mais significativos livros de jornalismo e comunicação do século XX. Na edição de 2014, o título mudou para Mediando a mensagem no século XXI, pois, segundo os autores, "forças da tecnologia e da globalização tornaram nosso objeto de estudo mais problemático, incluindo a profissão de notícias, as fronteiras da organização midiática e as relações institucionais entre mídia e sociedade"3 (SHOEMAKER; REESE, 2014, p. 13). A questão central dos 
autores norte-americanos são as forças que moldam o conteúdo da mídia e as mensagens que constituem o ambiente simbólico. Para isso, explicam conceitos, desenvolvem modelos e propõem quadros analíticos - "em resumo, pensamento teórico" (SHOEMAKER; REESE, 2014, p. 15).

Assim, os autores criam o conhecido modelo de hierarquia de influências, com cinco níveis de análise: sistemas sociais, instituições sociais, organizações de mídia, práticas de rotina e indivíduos. Para eles, "os modelos analíticos - até mesmo os mais simples - podem ter um efeito poderoso para direcionar nosso pensamento e ajudar a organizar um campo de pesquisa"4 (SHOEMAKER; REESE, 2014, p. 15).

Além dessa forte tradição dos estudos de newsmaking nos EUA, há na Europa pesquisas importantes sobre a produção de notícias. Alsina, autor espanhol estudioso das teorias da comunicação, defende a utilização da sociossemiótica nas pesquisas do campo, "pois é nela que se concentram as duas correntes fundamentais: a semiótica e a sociologia, embora também precisemos levar em conta as contribuições da psicologia e ainda da antropologia" (ALSINA, 2009, p. 30).

O sociólogo italiano Mauro Wolf, já citado anteriormente, também é referência nos estudos de newsmaking, tratando de critérios de noticiabilidade, valores-notícia e rotinas de produção. A respeito dos aspectos metodológicos da pesquisa sobre o newsmaking, Wolf (2012) destaca a técnica da observação participante, utilizada por diversos autores. Wolf diz que o importante é que a fase de observação, ou seja, da presença do pesquisador em campo, esteja ligada a hipóteses de pesquisa, "que seja orientada segundo aceitações teóricas precisas, e que não se constitua de maneira indistinguível e casual" (WOLF, 2012, p. 192).

No Brasil, Pereira Junior foi um dos pioneiros no estudo dos caminhos do processo de definição do que é notícia. Sua observação participante na redação do telejornal RJTV, da Rede Globo do Rio de Janeiro, investigou "como as rotinas de 
produção influenciam os jornalistas no momento de decidir se uma notícia deve ou não entrar em um telejornal e, consequentemente, definir o que as pessoas vão assistir" (PEREIRA JUNIOR, 2005, p. 6).

\section{Visada antropológica para o newsmaking}

Como visto, a forte tradição da sociologia americana nos estudos de newsmaking contribuiu para a construção de um pensamento teórico relativamente sólido e coeso. Em resumo, graças a esses trabalhos, hoje entendemos melhor como forças internas e externas atuam na produção da notícia. Mesmo tendo como principal finalidade a análise do impacto da mídia na sociedade, tais investigações acabaram por produzir conhecimentos importantes sobre o jornalismo.

Contudo, neste trabalho seguirei um caminho diferente de pesquisa, visando uma aproximação com o campo da antropologia - através da teoria ator-rede - para responder questões que são pertinentes ao campo do jornalismo. Dessa forma, em vez de utilizar a etnografia como um meio para chegar a uma generalização teórica, como fizeram os estudos sociológicos clássicos, proponho um caminho de pesquisa cujo resultado é a própria descrição, o próprio relato etnográfico, aqui entendido menos como resultado e mais como ação.

A teoria ator-rede (TAR) tem origem nos estudos de ciência e tecnologia e tem sido pensada ao longo dos últimos trinta anos por pesquisadores como os franceses Bruno Latour ${ }^{5}$ (1996, 2001, 2005, 2006, 2012) e Michel Callon (1980), a francesa Madeleine Akrich (2006), o inglês John Law (1992, 2004), a inglesa Marilyn Strathern (2014), o italiano Tommaso Venturini (2010), entre outros.

Uma das principais contribuições desse pensamento, que representa uma virada ontológica na antropologia, é que a produção de fatos científicos não deve partir do sujeito, mas da ação. Trata-se de um detalhe que desloca as interações e propõe uma simetrização entre sujeito e objeto. É no movimento, no curso das ações em rede que se dão o trabalho e o registro científico. 
Assim, segundo Latour (2012, p. 17-18), "o social não pode ser construído como uma espécie de material ou domínio e assumir a tarefa de fornecer uma 'explicação social' de algum outro estado de coisas". Os estudiosos da teoria ator-rede estão interessados, portanto, não numa sociologia do social, mas numa sociologia das associações. O social está sempre imerso na ação, ele é evento, e não ato. Isso quer dizer que a sociedade é consequência das associações e, por isso, ela não é dada de antemão.

Embora não veja a TAR como uma teoria, e faça críticas também ao termo "ator-rede", Latour gosta especialmente da analogia da sigla em inglês (ANT) com as formigas. "[É] perfeitamente adequado para um viajante cego, míope, viciado em trabalho, farejador e gregário. Uma formiga (ant) escrevendo para outras formigas, eis o que condiz muito bem com meu projeto!" (LATOUR, 2012, p. 28). É de novo utilizando a metáfora da formiga que o autor trata da diferença entre uma sociologia que se pretende explicativa e outra que mapeia as associações.

Vocês, cientistas sociais, sempre me desconcertam. Se você estudasse formigas, esperaria que elas aprendessem alguma coisa sobre seu estudo? Claro que não. Elas sabem, você não. Elas são professoras, você aprende com elas. Você explica o que elas fazem para você mesmo, para o seu próprio benefício ou para o dos outros entomólogos, não para elas, que não dão a mínima. O que o faz pensar que um estudo sempre supõe ensinar coisas às pessoas estudadas? (LATOUR, 2006, p. 347)

Entendo que não estabelecer papeis fixos a priori é um avanço epistemológico para os estudos de newsmaking. Imagine, por exemplo, um pesquisador que, munido do modelo de hierarquia de influências (SHOEMAKER; REESE, 2014), inicie a observação participante numa redação jornalística. Ele tenderá a olhar aquela realidade a partir das categorias previamente criadas, direcionando seus questionamentos de modo a confirmar ou refutá-las. Minimamente, ele já acredita que há hierarquias e influências, o que pode ser verdadeiro, mas não um pressuposto para análise. Assim, afasto-me da compreensão de Shoemaker e Reese de que os modelos analíticos direcionam o pensamento e organizam o 
campo de pesquisa, pois eles podem ofuscar a observação de controvérsias não esperadas pelo pesquisador, em nome de uma organização que é, por si só, uma performance. Entendo que os níveis não estão hierarquicamente organizados em cadeias de causação ou determinação:

Eles estão em uma rede achatada não hierárquica, mas revelam na sua constituição a influência de processos de distribuição dos efeitos locais e correspondentes localizações de características globais, caracterizando conectores entre os diversos âmbitos de uma mesma rede sem saltar de um ponto a outro (HOLANDA, 2014, p. 146).

Além disso, as influências, para utilizar o termo de Shoemaker e Reese, podem estar não somente entre sujeitos, mas entre humanos e não-humanos. "As perguntas etnográficas configuram-se em torno de como narrar uma ação e mostrar as conexões e rastros que ela deixa?" (LATOUR, 2005, p. 99). O estudo das associações, de acordo com a TAR, não considera a priori a ação do sujeito e nem sua superioridade em relação aos objetos não-humanos. Eles também agem. "A mediação com não-humanos é parte constitutiva do humano, mas a 'Constituição' da modernidade tentou nos fazer esquecer isso, insistindo na separação e na purificação dos híbridos em 'sujeitos' e 'objetos'"' (LEMOS, 2013, p. 21).

Quando consideramos os não-humanos, o número de atores em jogo é aumentado, pois os objetos acrescentam multiplicidade. Assim, uma descrição etnográfica à luz da TAR está em busca das diferentes entidades que atuam e é sempre um lugar de experimentação.

Se, para Latour (2005, p. 83), qualquer "ente" pode ter agência desde que produza algo em outro "ente" (seja humano ou não humano) e as agências não estão previamente determinadas, cabe à etnografia descrever o que faz fazer, identificar se um agente incide de algum modo no curso da ação de outro agente. (MÁXIMO et al., 2012, p. 313)

Em uma redação jornalística, podem ser múltiplos os humanos e nãohumanos em agência: jornalistas, programadores, designers, softwares diversos, manuais, documentos, textos, fotos, vídeos, celulares, computadores, valores 
institucionais, chats de comunicação entre jornalistas, e o próprio espaço físico da redação. Eles podem ser ora intermediários (elementos de uma rede que apenas transportam efeitos ou informação sem interferência), ora mediadores (elementos que modificam o curso da ação, provocando deslocamentos). Venturini (2010) aponta alguns caminhos para uma cartografia de controvérsias: "Você deve observar a partir de tantos pontos de vista quanto possíveis; você deve ouvir as vozes dos atores mais do que suas próprias presunções" ${ }^{\prime 6}$.

Por exemplo, Foletto (2017, p. 139-140) seguiu o processo de tradução do TwitCasting, software de transmissão ao vivo utilizado pela Mídia Ninja em 2013. Em uma das transmissões, ele identificou como atores um integrante da Mídia Ninja, um iPhone 4, o TwitCasting, a rede 3G de 1 Mbps, um chip de sinal 3G e a página na web do TwitCasting. Holanda (2014) mapeou os elementos atuantes na adaptação de veículos jornalísticos aos tablets, compreendendo, de maneira integrada, atores humanos e não-humanos, instituições, projetos de pesquisa e formas de financiamento. Por fim, Hemmingway, em seu livro Into the newsroom (2008), explorou como os jornalistas e as tecnologias digitais com as quais eles estão emaranhados constroem notícias televisivas no nível micro de prática, com destaque para a agência de um caminhão de satélite para transmissões ao vivo da rede $B B C$.

Investigar a prática jornalística (no caso do newsmaking, por meio de seu processo de produção), observando atores humanos e não-humanos, confere multiplicidade aos estudos em jornalismo que, de acordo com Lewis e Westlund, tradicionalmente dão ênfase às considerações centradas no humano - "como concepção de papeis individuais, constrangimentos organizacionais, normas profissionais, cultura nacional ou ideológica, e outros fatores socioculturais - sem suficientemente conhecer os distintos papeis da tecnologia e a tensão inerente entre 
humanos e máquinas"7. De acordo com os autores, para o estudo da produção da notícia, há uma necessidade acadêmica de pensar teoricamente e considerar as interconexões entre atores humanos (jornalistas, especialistas em tecnologia e pessoas de negócio), actantes tecnológicos (algoritmos, redes e sistemas de publicação de conteúdo) e audiências (conjuntos de públicos distintos em certas plataformas, dispositivos ou aplicações). Dessa forma, eles propõem os quatro As - atores, actantes, audiências e atividades -, introduzindo uma matriz de visualização de suas relações e propondo uma agenda de pesquisa para estudálos de forma mais holística.

Com essas considerações, não pretendo encerrar ou mesmo dar conta de explicar a teoria ator-rede ${ }^{8}$, que, vale lembrar, tem sido estudada em diversas áreas do conhecimento. Latour sequer fala sobre jornalismo. Por isso, meu objetivo foi, a partir da apresentação das ideias-chave da TAR, aproximá-la dos estudos em jornalismo mais recentes, de modo a justificar e propor uma escolha metodológica para os estudos de newsmaking que pretendem analisar a mídia.

\section{Em busca de uma etnografia possível para os estudos de newsmaking}

De acordo com Lago (2007, p. 48), a relação entre antropologia e jornalismo remonta pelo menos ao início do século XX, "quando a Escola de Chicago voltou seu olhar para o meio urbano e estudou sua relação com a mídia a partir de um trabalho com feições antropológicas". Assim, é a antropologia que fundamenta metodologicamente pesquisas sobre o newsmaking.

Para Peirano, a antropologia é a ciência social que pede para ser ultrapassada e superada; que mantém viva a consciência de que o que se aprende ou descobre é sempre provisório e contextualizado. Assim, nem todo bom antropólogo é

Tradução livre do original: "such as individual role conceptions, organizational constraints, professional norms, national culture or ideology, and other socio-cultural factors - without sufficiently acknowledging the distinct role of technology and the inherent tension between human and machine approaches." (LEWIS; WESTLUND, 2014, p. 20) como o livro de Hemmingway (2008). A bibliografia da TAR está organizada por ordem alfabética e temática no ANT Resource, projeto mantido pelo Departamento de Sociologia da Universidade de Lancaster, na Inglaterra. Disponível em: <https://goo.gl/MVHKQL>. 
necessariamente um etnógrafo. "Há aqueles mais inclinados e os menos atraídos para a pesquisa de campo. Mas todo bom antropólogo aprende e reconhece que é na sensibilidade para o confronto ou o diálogo entre teorias acadêmicas e nativas que está o potencial de riqueza da antropologia." (PEIRANO, 1995, p. 45)

Boyer (2013), antropólogo que fez etnografias em uma agência de notícias, um portal online e uma rádio para investigar o newsmaking na era digital, reconheceu semelhanças entre as duas áreas.

Embora os antropólogos se considerem pessoalmente como trabalhadores de campo, a verdade é que passamos a maior parte do tempo como trabalhadores da tela, mesmo no "campo". Como meus parceiros de pesquisa jornalística, meu dia de trabalho se desenrola na frente de um computador pessoal, muitas vezes com um programa de processamento de texto aberto na minha área de trabalho .

De acordo com Velho (1978, p. 123), a antropologia, embora sem exclusividade, tradicionalmente identificou-se com os métodos de pesquisa ditos qualitativos: "A observação participante, a entrevista aberta, o contato direto, pessoal, com o objeto investigado constituem sua marca registrada".

Lago chama atenção para o fato de que as pesquisas em jornalismo, quando interagem com a antropologia, fazem uma aplicação quase mecânica do método, perdendo, com isso, o olhar disciplinado pela antropologia, fundamentalmente marcado pela suspeição em relação à própria pesquisa. "Por isso, talvez não seja exagero afirmar que o encontro entre antropologia e jornalismo pode ser marcado mais por suas ausências do que pelas presenças" (LAGO, 2007, p. 55).

Visando propor um caminho para essa limitação metodológica, apresento a seguir algumas características que considero essenciais para a etnografia do processo de produção da notícia, conferindo especificidade aos estudos de

Tradução livre do original: "Although anthropologists happily consider themselves as fieldworkers at heart, the truth is that we spend most of our time as screenworkers, even in "the field". Like my journalistic research partners, my average workday unfolds in front of a personal computer, often with a word-processing program open on my desktop." (BOYER, 2013, p. 11) 
newsmaking. Não se trata de um guia, mas de um esforço metodológico que pode auxiliar os pesquisadores que utilizam o método etnográfico.

\section{A entrada do pesquisador na redação}

A negociação que resulta na entrada do pesquisador na redação nem sempre é fácil e, por vezes, dura dias ou até mesmo meses; é o "processo de ser aceito pelo grupo" (LAGO, 2007, p. 51). Há alguns fatores subjetivos em jogo, como o perfil do jornalista - seja um editor, chefe de reportagem ou chefe de redação. Alguns são mais abertos ao contato com acadêmicos, outros relutam por desconfiarem das intenções do pesquisador (não é rara a percepção de que a Academia só critica) ou por falta de tempo, já que sabem que precisarão mudar suas rotinas para receber alguém "de fora".

Aliado a isso, existe o fator burocrático. Se o contato é feito com um repórter, ele normalmente precisa pedir autorização ao editor e este, ao chefe imediato. Quanto maior a redação, maiores as hierarquias a serem respeitadas. Por isso, se o pesquisador tiver contato com um profissional que ocupa um cargo de chefia, sua entrada na redação será menos burocrática.

Mas nem sempre isso é suficiente. Para fazer pesquisa nos veículos ligados à Rede Globo, por exemplo, é necessário cumprir diversas etapas junto ao Globo Universidade, que tem um setor só para isso. O pesquisador precisa enviar um projeto detalhando seus objetivos de investigação, o que pretende fazer (entrevistas, observação participante, etc.), por quanto tempo e com quantas pessoas. Após análise, que inclui idas e vindas com pedidos de mais informações e assinatura de documentos pela universidade, a equipe decide se aprova ou não a solicitação, e de que forma. Em minha pesquisa de mestrado, por exemplo, realizada em 2013, solicitei uma entrevista presencial com o editor-chefe do G1, mas recebi aprovação somente para entrevista por e-mail ${ }^{10}$. 
Com isso, destaco que existem fatores alheios à vontade do pesquisador que podem inviabilizar a realização do trabalho. Assim, a etapa de negociação da entrada na redação exige tempo, esforço e até um pouco de sorte, e deve constar, inclusive, no relato etnográfico.

\section{A duração do campo}

A aprovação da entrada do pesquisador na redação não significa que ele poderá permanecer pelo tempo que desejar. Não é raro que o período de observação participante seja breve ou menor do que o inicialmente solicitado. Mesmo pesquisas longas, como as de Tuchman e Gans, que duraram 10 anos, não ocorreram de forma ininterrupta.

Como essa decisão também é alheia à vontade do pesquisador, surge a pergunta: quanto tempo preciso permanecer na redação para que possa chamar minha pesquisa de etnografia? Esta dúvida faz com que, muitas vezes, sejam utilizados sinônimos como "olhar etnográfico", "inspiração etnográfica", ou "experiência etnográfica". Não definindo seu trabalho como etnografia, o pesquisador se sente desobrigado de fazer reflexões essenciais, a respeito, por exemplo, de sua própria presença - que modifica o campo - e da percepção das subjetividades pelos pesquisados e por si mesmo. Assim, esse "meio do caminho etnográfico" empobrece a pesquisa e diminui muito seu potencial de descoberta.

Buscando encontrar uma saída para esse impasse, proponho pensar a noção de campo de maneira estendida. O trabalho de Giumbelli (2002) é essencial para embasar essa compreensão, pois ele discute uma antropologia fora do trabalho de campo. Recorrendo à sua própria trajetória de pesquisa, que, no mestrado e doutorado, explorou basicamente material histórico e relatos textuais, Giumbelli afirma que o objetivo fundamental da pesquisa etnográfica deve ser buscado a partir de uma variedade de fontes, cuja pertinência é avaliada pelo acesso que propiciam aos mecanismos sociais e aos pontos de vista em suas manifestações concretas. 


\begin{abstract}
Ora, há situações etnográficas em que essas fontes são exatamente os "documentos materiais fixos" a que se refere Malinowski. Em se tratando de um objeto histórico, essas serão as únicas fontes para o trabalho de um antropólogo. Mas mesmo quando estivermos diante de um objeto contemporâneo, é possível que a análise de fontes documentais seja mais indicada do que a busca de um "contato o mais íntimo possível com os nativos." (GIUMBELLI, 2002, p. 102)
\end{abstract}

Esse entendimento do trabalho de campo compreende que ele não se restringe à observação participante, mas começa no primeiro contato que o pesquisador tem com seu objeto, normalmente durante a elaboração do projeto de pesquisa. Assim, a etnografia feita numa tese, por exemplo (que dura, em média, quatro anos), deve refletir, no material coletado nesse período, o que já se sabia de antemão sobre os entrevistados e a própria rotina daquela redação. No caso do pesquisador jornalista, é impossível negar que ele detém determinado conhecimento sobre uma redação mesmo antes de entrar fisicamente nela, e é essencial que ele reflita sobre sua posição. É a observação do familiar, como aponta Velho (1978):

O processo de estranhar o familiar torna-se possível quando somos capazes de confrontar intelectualmente, e mesmo emocionalmente, diferentes versões e interpretações existentes a respeito de fatos, situações. 0 estudo de conflitos, disputas, acusações, momentos de descontinuidade em geral é particularmente útil, pois, ao se focalizarem situações de drama social, podem-se registrar os contornos de diferentes grupos, ideologias, interesses, subculturas, etc., permitindo remapeamentos da sociedade. (p. 131-132)

Nesse sentido, a noção de campo para além da presença física do pesquisador inclui a antropologia do ciberespaço, que hoje já possui reconhecimento científico, mas foi objeto de críticas num passado recente. De acordo com Máximo et al. (2012, p. 300), "a noção de etnografia virtual não remete à criação de um novo método, mas à importância de se colocar em foco os pressupostos que estão na base da etnografia juntamente com aspectos relativos às tecnologias que se tornam centrais e constitutivos desses contextos que estamos estudando". Uma troca de e-mails entre pesquisador e pesquisado após o trabalho de campo, por 
exemplo, solicitando mais informações sobre determinado assunto que não pôde ser tratado presencialmente, faz parte desse trabalho de campo.

Assim como não começa na observação participante, o campo também não se encerra com a saída do pesquisador da redação. É o relato etnográfico que corta a rede, no sentido utilizado por Strathern (2014) - a rede teoricamente não tem limites, mas etnograficamente sofre inflexões. Como visto anteriormente, Latour traz para o primeiro plano o ato de compor relatos, que ocorre quando traçamos conexões sociais. Nesse sentido, descrever é fazer desdobramentos.

Desdobrar significa simplesmente que, no relato conclusivo da pesquisa, o número de atores precisa ser aumentado; o leque de agências que levam os atores a agir, expandido; a quantidade de objetos empenhados em estabilizar grupos e agências, multiplicada; e as controvérsias em torno de questões de interesse, mapeadas. (LATOUR, 2012, p. 201)

Portanto, mais importante do que o tempo que o pesquisador permanece na redação, é sua consciência epistemológica dessa noção de campo. Tal entendimento acaba por evitar a aplicação mecânica do método a que se referiu Lago (2007). O campo termina com o ponto final da pesquisa, e pode recomeçar com a abertura de uma nova caixa-preta.

\section{A observação participante}

A observação participante é a principal técnica utilizada no método etnográfico, e sua aplicação contribuiu para a própria legitimação da antropologia enquanto disciplina específica ${ }^{11}$. Ela está relacionada ao procedimento do antropólogo de "sair" de sua cultura e vivenciar a cultura do grupo que estuda - o "objetivo é enfronhar-se de tal forma na vida dos grupos estudados a ponto de poder assimilar de alguma forma sua cultura, que poderá assim ser descrita" (LAGO, 2007, p. 51).

11 Nesse sentido, é seminal o livro Argonautas do pacífico ocidental, de Bronislaw Malinowski, publicado em 1922 , no qual ele descreve o trabalho de campo realizado entre os melanésios da costa nordeste da Nova Guiné, durante a década de 1910 (Cf. MALINOWSKI, 1976). 
Numa redação jornalística, o pesquisador observa a rotina produtiva de uma ou mais editorias ou setores, sempre anotando no diário de campo aspectos que a demarcam. Além disso, pode acompanhar reuniões de pautas (nelas, normalmente, não utiliza o gravador) e até saídas para pautas, ou seja, o jornalista pesquisador em campo pode acompanhar o trabalho de campo do jornalista pesquisado. A presença do pesquisador nestes dois momentos (reunião de pauta e saída para pauta) normalmente resulta de uma negociação; não é algo que se consegue facilmente, justamente por serem ocasiões menos controladas.

Como pontuado anteriormente, a redação é um ambiente familiar ao jornalista estudioso do newsmaking. Matta (1993) lembra que as pesquisas sobre populações urbanas devem transformar "familiar em exótico", em vez de "exótico em familiar". No contexto do jornalismo, isso traz algumas consequências bem lembradas por Lago (2007):

A utilização da observação participante reveste-se de alguns complicadores a mais, já que o campo é marcado por uma auto-referencialidade extrema que pode deixar o pesquisador bastante inclinado a aceitar como dados as explicações que os atores tecem sobre o campo. Ainda mais se pensarmos que muitos dos que pesquisam o jornalismo são também jornalistas e, portanto, sujeitos a uma percepção bastante marcada pelo próprio campo. (p. 57)

No entanto, a proximidade entre pesquisador e pesquisados pode ser benéfica, na medida em que, justamente por aquele ser também um "nativo" do campo, é maior sua crítica a respeito do que observa e ouve. Além disso, citando Bourdieu (1999, p. 697), Lago (2007, p. 61) afirma que "a proximidade social e a familiaridade asseguram efetivamente duas das condições principais de uma comunicação não violenta, na medida em que não contrapõem dois sujeitos (pesquisador e pesquisados) que falam de lugares hierarquicamente distintos". Assim, é essencial que essa duplicidade do pesquisador (jornalista pesquisando jornalismo) esteja presente e seja problematizada no relato etnográfico.

Lago também considera importante que o pesquisador assuma a subjetividade inerente à pesquisa. "Incorporamos da mesma forma que o campo jornalístico, 
as presenças da neutralidade de nossas perspectivas, ao mesmo tempo em que, novamente como o campo, deixamos de incorporar a subjetividade (do encontro, do pesquisador), apagando o narrador da narrativa" (LAGO, 2007, p. 60). Segundo a autora, isso faz com que o pesquisador valorize o comportamento dito em vez do observado, e a descrição etnográfica se torne muito mais um relato de conversas com os observados do que uma observação participante propriamente dita.

Rastrear as múltiplas agências de humanos e não-humanos no curso da ação também é essencial à observação participante. Um pesquisador da teoria ator-rede tem um olhar expandido sobre o campo, pois está atento a quem ou o que faz fazer o quê, e não somente aos sujeitos - no caso, os próprios jornalistas. Eis a riqueza dessa escolha metodológica: a observação das agências em rede.

\section{As entrevistas com jornalistas}

A entrevista não é só uma das técnicas do método etnográfico. Ela é, por excelência, a principal técnica de coleta de informações do trabalho jornalístico, e uma possibilidade aberta para o diálogo, tendo em vista o entendimento de Medina (1986) de que nem toda entrevista é um diálogo. "Quando ocorre uma entrevista dirigida por um questionário estanque ou motivada por um entrevistador também fixado em suas ideias pré-estabelecidas (em geral, coincidentes com o questionário) ou no autoritarismo impositivo, o resultado frustra o receptor" (p. 6).

A entrevista é um processo subjetivo, no qual também se pode perceber a agência de humanos e não-humanos. Embora seja um diálogo entre pesquisador e pesquisado, na maioria das vezes a entrevista conta com um gravador, ou seja, um objeto técnico que não é neutro. De forma geral, o entrevistado tende a agir mais naturalmente nas conversas informais não gravadas, ao passo que, nas conversas formais gravadas - no momento específico da entrevista -, ele ou ela tende a pensar mais antes de falar, e ponderar opiniões mais polêmicas.

O pesquisador deve, então, avaliar o custo-benefício do gravador no trabalho de campo. Quando o utiliza, corre o risco da perda de espontaneidade do entrevistado, mas ganha em rigor do registro de sua fala; ao abrir mão do 
gravador, surge a possibilidade de diálogos inesperados, mas quem perde em naturalidade é o pesquisador, que necessita se preocupar em anotar tudo, para poder compor com veracidade o relato escrito.

As entrevistas do pesquisador de newsmaking são feitas, em sua maioria, com jornalistas que, além de dominar a técnica, estão acostumados com a utilização do gravador. Assim, normalmente não há resistência quando o pesquisador pergunta se pode gravar a conversa. Vale destacar que em outros momentos da observação participante, como em reuniões de pauta e nas saídas para acompanhamento de pautas, o gravador não é utilizado, e o registro deve ser feito no diário de campo. Aliás, se o entrevistado dá informações em off, ou seja, pede para que não sejam divulgadas, isso deve ser respeitado pelo pesquisador.

A entrevista é o momento especial do ouvir, que, "alcançado mediante entrevistas em profundidade, abertas, mas também diálogos causais, ajuda o pesquisador a perceber o sentido das ações que observa" (LAGO, 2007, p. 52). Por isso, ela não deve ser tratada simplesmente como uma coleta de dados para a pesquisa e, a menos que solicitado, não é recomendável omitir o nome do entrevistado. Ele ou ela tem agência no curso da ação observada, que seria outra se fossem distintos os entrevistados.

Cabe ao pesquisador estar atento a questões contextuais que têm influência no relato etnográfico. Por exemplo, "das 10 pessoas que entrevistei naquela redação, quantas são mulheres? E quantas são negras? Isso faz diferença no curso da ação, pode provocar controvérsias?" Estamos falando, portanto, de alteridade. Veiga (2015, p. 60) lembra que as chamadas epistemologias da diferença/alteridade, feministas e pós-modernas, "têm promovido interessantes perspectivas para um pensamento mais complexo sobre o mundo, com vistas à sua transformação, negando a reprodução de hegemonias excludentes cujos impactos sociais são devastadores". É dessa forma que vão surgir, por exemplo, os conflitos éticos, os constrangimentos organizacionais e as relações de poder, que não aparecem como categorias estabilizadas, mas compõem a observação e o diálogo entre pesquisador e pesquisado. 


\section{O diário de campo e o relato etnográfico}

Na medida em que a rede é o traço deixado por um agente em movimento, seu registro se torna extremamente importante no curso da pesquisa. Para isso, Latour (2012) propõe uma lista de cadernos: um diário da própria pesquisa; outro para registrar os itens em ordem cronológica e enquadrá-los em categorias; um terceiro para registros ad libitum, ou seja, à vontade; e o último para registrar efeitos do relato escrito nos atores. É por meio dos cadernos que o autor traça o caminho do rigor do cientista social com sua pesquisa, já que o que parece fácil num primeiro momento tende a ser extremamente complexo quando colocado em prática.

Assim, o diário de campo deve ser escrito de forma bem detalhada, mesmo que nem tudo se transforme em texto etnográfico na pesquisa. Além das conversas informais dentro e fora da redação (como almoços, por exemplo), pode-se anotar sensações quanto ao clima de trabalho na redação e detalhes de seu espaço (distribuição espacial das editorias, lugar onde senta a chefia, etc.).

Miranda (2016), em sua etnografia na redação do programa Bem estar, observou a preocupação com a decoração e cenografia, os efeitos óticos e sonoros, e a utilização de trilha para produzir tensão. "As figuras e os gestos corporais que codificam a informação, produzindo dramaticidade no ato da apresentação, também são identificadas no produto da Rede Globo, que buscou um jornalista com formação em artes dramáticas para ancorar o programa" (p. 8-9).

Encerrada a observação participante, o pesquisador inicia a descrição escrita de sua etnografia no documento de pesquisa (dissertação, tese ou artigo). Lemos (2013, p. 91) recomenda: "descreva, descreva, descreva e você encontrará os principais mediadores (actantes), os intermediários (que transportam, mas não mudam nada), as ideologias, as forças, os poderes, as razões, as estruturas e as agências circulando".

Latour também enfatiza que um bom relato da TAR é uma narrativa, descrição ou proposição na qual todos os atores fazem alguma coisa e não ficam apenas observando. "Em vez de simplesmente transportar efeitos sem transformá- 
Ios, cada um dos pontos no texto pode se tornar uma encruzilhada, um evento ou a origem de uma nova translação." (LATOUR, 2012, p. 198)

A escrita de textos é ofício do jornalista, mas a primeira coisa que ele aprende na universidade é "tire a opinião do texto". Embora seja inatingível, a objetividade funciona como um método para o relato jornalístico, de modo a se descrever de maneira mais assertiva os acontecimentos. Não vou me aprofundar neste terreno árido da objetividade, mas a mencionei aqui para enfatizar que o relato etnográfico segundo a TAR, embora descritivo, é permeado por subjetividades e avesso a qualquer neutralidade. É na descrição e vigilância sobre sua própria agência no campo que o pesquisador constrói seu relato etnográfico.

\section{Referências}

AKRICH, M. La description de objets techniques. In: AKRICH, M.; CALLON, M.; LATOUR, B. Sociologie de la traduction: textes fondateurs. Paris: Mines, 2006.

ALSINA, M. R. A construção da notícia. Petrópolis: Vozes, 2009.

BOURDIEU, P. (Coord.). A miséria do mundo. Petrópolis: Vozes, 1999.

BOYER, D. The life informatic: newsmaking in the digital era. Ithaca: Cornell University Press, 2013.

CALLON, M. Struggles and negotiations to define what is problematic and what is not: the sociology of translation. In: KNORR, K.; KROHN, R.; WHITLEY, D. (Org.). The social process of scientific investigation: sociology of the sciences yearbook. Boston: Reidel, 1980. p. 197-219. 
FOLETTO, L. Um mosaico de parcialidades na nuvem coletiva: rastreando a Mídia Ninja (2013-2016). 2017. Tese (Doutorado) - Programa de Pós-Graduação em Comunicação e Informação, Faculdade de Biblioteconomia e Comunicação da Universidade Federal do Rio Grande do Sul, Porto Alegre, 2017.

FONTCUBERTA, M. La noticia: pistas para percibir el mundo. Barcelona: Paidós, 1993.

GANS, H. J. Deciding what's news: a study of CBS evening news, NBC nightly news, Newsweek and Time. Evanston: Northwestern University Press, 2004.

GIUMBELLI, E. Para além do "trabalho de campo": reflexões supostamente malinowskianas. Revista Brasileira de Ciências Sociais, São Paulo, v. 17, n. 48, p. 91-107, fev. 2002.

HALL, S. Da diáspora: identidades e mediações culturais. Belo Horizonte: UFMG, 2009

HEMMINGWAY, E. Into the newsroom: exploring the digital production of regional television news. London: Routledge, 2008.

HOHLFELDT, A. Hipóteses contemporâneas de pesquisa em comunicação. In: HOHLFELDT, A.; MARTINO L. C.; FRANÇA, V. Teorias da comunicação. Petrópolis: Vozes, 2014. p. 187-240.

HOLANDA, A. Traduzindo o jornalismo para tablets com a teoria ator-rede. 2014. Tese (Doutorado) - Programa de Pós-Graduação em Comunicação e Culturas Contemporâneas da Universidade Federal da Bahia, Salvador, 2014. 
LAGO, C. Antropologia e jornalismo: uma questão de método. In: LAGO, C.; BENETTI, M. Metodologia de pesquisa em jornalismo. Petrópolis: Vozes, 2007. p. 48-66.

LATOUR, B. The powers of association. In: LAW, J. (Org.). Power, action and belief: a new sociology of knowledge? New York: Routledge: Kegan Paul, 1986. p. 264-280.

. A esperança de Pandora: ensaios sobre a realidade dos estudos científicos. Bauru: Edusc, 2001.

Jamais fomos modernos: ensaio de antropologia simétrica. São Paulo: Editora 34, 2005.

. Como terminar uma tese de sociologia: pequeno diálogo entre um aluno e seu professor (um tanto socrático). Cadernos de Campo, São Paulo, n. 14-15, p. 340-352, 2006.

Reagregando o social: uma introdução à teoria do ator-rede. Salvador: Edufba; Bauru: Edusc, 2012.

LATOUR, B.; WOOLGAR, S. A vida de laboratório: a produção dos fatos científicos. Rio de Janeiro: Relume Dumará, 1997.

LAW, J. Notes on the theory of the Actor-Network: ordering, strategy and heterogeneity. Systems Practice, Norwell, v. 5, n. 4, p. 379-393, 1992.

After method: mess in social science research. New York: Routledge, 2004.

LEMOS, A. A comunicação das coisas: teoria ator-rede e cibercultura. São Paulo: Annablume, 2013. 
LEWIS, S.; WESTLUND, O. Actors, actants, audiences, and activities in crossmedia news work. Digital Journalism, v. 3, n. 1, p. 19-37, 2014

MALINOWSKI, B. Argonautas do pacífico ocidental: um relato do empreendimento e da aventura dos nativos nos arquipélagos da Nova Guiné melanésia. São Paulo: Abril Cultural, 1976.

MATTA, R. da. Relativizando: uma introdução à antropologia social. Rio de Janeiro: Rocco, 1993.

MÁXIMO, E. et al. A etnografia como método: vigilância semântica e metodológica nas pesquisas no ciberespaço. In: MALDONADO, E. et al. Epistemologia, investigação e formação científica em comunicação. Rio do Sul: Unidavi, 2012. p. 293-319.

MEDINA, C. Entrevista: o diálogo possível. São Paulo: Ática, 1986.

MIRANDA, A. Hibridação no jornalismo especializado em saúde: resultados preliminares de uma experiência etnográfica. In: ENCONTRO NACIONAL DE PESQUISADORES EM JORNALISMO, 14., nov. 2016, Palhoça. Anais... Palhoça: Unisul, 2016. 13 p.

PEIRANO, M. A favor da etnografia. Rio de Janeiro: Relume-Dumará, 1995.

PEREIRA JUNIOR, A. E. V. Decidindo o que é notícia: os bastidores do telejornalismo. Porto Alegre: EDIPUCRS, 2005.

PIMENTEL, A.; TEMER, A. C. Newsmaking in Portuguese: uma discussão das hipóteses de Gaye Tuchman no contexto brasileiro. Comunicação \& Informação, Goiânia, v. 15, n. 2, p. 116-132, jul./dez., 2012. 
SHOEMAKER, P.; REESE, S. Mediating the message in the 21st century: a media sociology perspective. New York: Routledge, 2014.

STRATHERN, M. O efeito etnográfico e outros ensaios: Marilyn Strathern. São Paulo: Cosac Naif, 2014.

TRAQUINA, N. As notícias. Revista de Comunicação e Linguagens, Lisboa, n. 8, p. $29-40$, dez. 1988

TUCHMAN, G. Making news: a study in the construction of reality. New York: The Free Press, 1978.

VEIGA, M. Saberes para a profissão, sujeitos possíveis: um olhar sobre a formação universitária dos jornalistas e as implicações dos regimes de poder-saber nas possibilidades de encontro com a alteridade. 2015. Tese (Doutorado) - Programa de Pós-Graduação em Comunicação e Informação, Faculdade de Biblioteconomia e Comunicação da Universidade Federal do Rio Grande do Sul, Porto Alegre, 2015.

VELHO, G. Observando o familiar. In: NUNES, E. (Org.). A aventura sociológica. Rio de Janeiro: Zahar, 1978.

VENTURINI, T. Diving in magma: how to explore controversies with Actor-Network theory. Public Understanding of Science, v. 19, n. 3, p. 258-273, 2010.

WOLF, M. Teorias das comunicações de massa. São Paulo: Martins Fontes, 2012. 